\title{
CD276 (B7H3) improve cancer stem cells formation in cervical carcinoma cell lines
}

\author{
Jianfeng Shi ${ }^{1 \#}$, Haishan Zhao ${ }^{2 \#}$, Huan Lian ${ }^{1}$, Linnan $\mathrm{Ke}^{1}$, Lei Zhao ${ }^{1}$, Chunren Wang ${ }^{1}$, Qianqian Han ${ }^{1}$ \\ ${ }^{1}$ Division of Biomaterials, Department of Medical Devices, Chinese National Institutes for Food and Drug Control, Beijing, China; ${ }^{2}$ Guangdong \\ Provincial Key Laboratory of South China Structural Heart Disease, Guangdong Cardiovascular Institute, Guangdong Provincial People's Hospital, \\ Guangzhou, China \\ Contributions: (I) Conception and design: C Wang, Q Han; (II) Administrative support: H Zhao; (III) Provision of study materials or patients: J Shi, \\ H Zhao, Q Han; (IV) Collection and assembly of data: J Shi, H Zhao; (V) Data analysis and interpretation: J Shi, H Zhao; (VI) Manuscript writing: \\ All authors; (VII) Final approval of manuscript: All authors. \\ \#These authors contributed equally to this work. \\ Correspondence to: Chunren Wang, Qianqian Han. Division of Biomaterials, Department of Medical Devices, Chinese National Institutes for Food \\ and Drug Control, Beijing 102629, China. Email: chunrenwang@263.net; hanqianqian2005@163.com.
}

\begin{abstract}
Background: Cancer stem cells (CSCs) have been considered as a potential therapeutic target for cervical carcinoma. CD 276 is a well-known immune check point molecular, but its relationship with cervical CSCs was still unclear.

Methods: HeLa cell lines were obtained as cervical carcinoma in vitro model. HeLa cell Sphere formation culture was performed and CD276, OCT4 and SOX2 expression were determined by RT-qPCR. Transiently transfection and siRNA interference were used to modify CD276 expression. HeLa cell colony has been counted and cell proliferation was assessed by MTT assay. The relationship between CD276 and chemotherapy resistance of HeLa cell were evaluated by cisplatin treatment. Additionally, the mice model of xenograft tumor was established and CD276's function was evaluated in vivo.

Results: Here, we demonstrate that the expression of CD276 is positively correlated with the amount of sphere-forming cells in HeLa cell lines. Overexpression of CD276 causes the inhibition of HeLa cells' sphere formation, colony formation and cell viability. Meanwhile, the downregulation of CD276 leads to the other way. We also demonstrate that CD276 contributes to the chemotherapy resistance in the cell line. Furthermore, we verify the CD276's function on HeLa xenotransplantation mice model.
\end{abstract}

Conclusions: These results suggest that CD276 elevates the self-renewal capacity of HeLa CSCs.

Keywords: CD276; cancer stem cells (CSCs); cervical carcinoma; HeLa cells; sphere formation cells

Submitted Dec 22, 2019. Accepted for publication Nov 20, 2020.

doi: $10.21037 /$ tcr-19-2910

View this article at: http://dx.doi.org/10.21037/tcr-19-2910

\section{Introduction}

Cervical carcinoma is the third most common female cancer in developing countries (1). Several factors such as HPV infection or chlamydia associated multiple pregnancies cause an increasing incidence of cervical carcinoma worldwide (2). Typically, carcinoma cells do not perform synchronized proliferation and self-renewal life cycles. A theory postulates that a small fraction of cancer cells, named as cancer stem cells (CSCs) (3), are answerable for the cancer initiation, development and migration. Furthermore, their roles in cancer therapy resistance and recrudesce were also reported (4-6). Thus, cervical CSCs have been considered as a potential clinical target (7).

Several studies have been working on the characterization of CSCs in cervical carcinoma $(8,9)$. As the critical role CSCs play in resistance of chemotherapy and radiotherapy of cervical carcinoma (10), it has been considered for further development of new therapeutic target (11-14). 
Currently, several markers have been discovered for cervical CSCs, including cytokeratin (CK) 8, CK 17, CD44, and ALDH1 (8,15-17). However, it is unsatisfactory to identify cervical CSCs based on currently available technologies, the underlying mechanisms of cervical CSCs differentiation, proliferation and migration remain poorly illustrated.

CD276, also named B7H3, work as an immune checkpoint molecule (18). It expresses in most normal tissues at a low level, but shows a significantly high abundance in variety of cancer cells including breast, colorectal, glioma, kidney, liver, lung, and cervical (19-21). Recent discoveries indicate that CD276 is associated with poor prognosis in clinical $(21,22)$. Several studies also claim that CD276 also displays CSCs-like traits in different cancers. However, even with the high-level expression of CD276 in cervical carcinoma, the potential role of CD276 in cervical CSCs has not been reported. Therefore, this study intends to articulate the CD276's function in cervical cell metastasis and chemotherapy resistance.

We present the following article in accordance with the ARRIVE reporting checklist (available at http://dx.doi. org/10.21037/tcr-19-2910).

\section{Methods}

\section{Etbical Statement}

Experiments were performed under a project license [No. 2019(A)027] granted by committee Chinese National Institute for Food and Drug Control, in compliance with Regulations for the Administration of Affairs Concerning Experimental Animals published by the Chinese Government.

\section{Cell lines and cell culture}

HeLa cell lines were obtained from the Type Culture Collection of the Chinese Academy of Sciences (Shanghai, China) and cultured according to the manuals. In details, cells were maintained in high glucose DMEM with $10 \%$ fetal bovine serum, $100 \mathrm{IU} / \mathrm{mL}$ penicillin $\mathrm{G}$ and $100 \mu \mathrm{g} / \mathrm{mL}$ streptomycin at $37{ }^{\circ} \mathrm{C}$ in a humidified $5 \% \mathrm{CO}_{2}$ incubator.

\section{HeLa cell sphere formation culture}

Single cell suspensions were suspended at a density of 5,000 cells/mL in serum-free DMEM/F12 supplemented with $100 \mathrm{IU} / \mathrm{mL}$ penicillin, $100 \mu \mathrm{g} / \mathrm{mL}$ streptomycin, $20 \mathrm{ng} / \mathrm{mL}$ human recombinant epidermal growth factor,
$10 \mathrm{ng} / \mathrm{mL}$ human recombinant basic fibroblast growth factor, 2\% B27 supplement without vitamin A and 1\% N2 supplement and seeded into ultra-low attachment 6-well plates. Suspension cultures were continued for 6 days until spheres were formed.

\section{Real-time quantitative PCR microarray}

The PCR reaction was performed in the LightCycler ${ }^{\circledR}$ 96 System with the following amplification profile: preincubating at $95^{\circ} \mathrm{C}$ for $3 \mathrm{~min}, 40$ cycles at $95^{\circ} \mathrm{C}$ for $15 \mathrm{~s}$, $60{ }^{\circ} \mathrm{C}$ for $15 \mathrm{~s}$ and $72{ }^{\circ} \mathrm{C}$ for $20 \mathrm{~s}$ and melting at $95^{\circ} \mathrm{C}$ for $10 \mathrm{~s}, 65^{\circ} \mathrm{C}$ for $60 \mathrm{~s}$, and $97^{\circ} \mathrm{C}$ for $1 \mathrm{~s}$. RNA samples were harvest and purify. After synthesized the first strand cDNA, RT-qPCR was performed. The RT-qPCR primer is: sox2 $\mathrm{F}$ : 5'-TTACCTCTTCCTCCCACTCC-3'; sox 2 R: 5'-ACCCCTCCCATTTCCCTC-3'; oct4 F: 5'-CCTGTCTCCGTCACCACT-3'; R: 5'-ACTTCACCTTCCCTCCAA-3'; CD276 F: 5'-GCAGCCTCTGAAACACTC-3'; CD276 R: 5'-TTGGGAATCATGTCCATT-3'; gapdh-Q1 F : 5' - CCTGAGCTGAACGGGAAGC-3'; R : 5'-AGGTGGAGGAGTGGGTGTCG-3'. The data were analyzed by $-\Delta \Delta$ Ct.

\section{HeLa cell colony formation culture}

HeLa cells $\left(0.5 \times 10^{3}\right)$ were seeded into $100 \mathrm{~mm}^{2}$ cell culture plates and cultured for 7 to 12 days. Colonies were fixed with paraformaldehyde, stained with crystal violet, and counted.

\section{Transiently transfection of CD276}

The pcDNA3.1-CD276 or control pcDNA3.1-LacZ plasmid vectors were transfected into HeLa cells using Lipofectamine 2000 transfection reagent, according to the manufacturer's instructions. The cells were resuspended in complete medium (DMEM supplemented with $10 \%$ fetal bovine serum) for $48 \mathrm{~h}$.

\section{Cell viability assay}

HeLa cells viability were determined by MTT assay. Briefly, cells were seeded in 96-well plates that were precoated with Matrigel, and various concentrations of cisplatin were added at the beginning, co-incubated for 12 or $24 \mathrm{~h}$. After changing to fresh medium without cisplatin, cells were cultured for another $72 \mathrm{~h}$. The MTT reagent was 


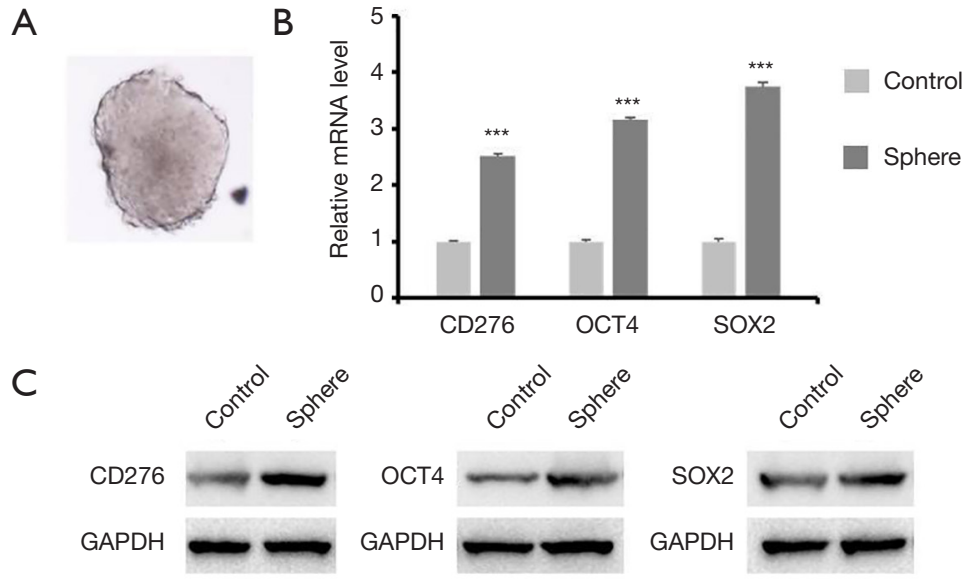

Figure 1 CD276 acts as a potential stem cell marker in Hela cells. (A) The sphere of Hela cells ( $\times 100)$; (B) CD276 is highly expressed in sphere-forming cells; (C) CD276 and CSCs markers are highly expressed in sphere-forming cells in protein level. Results are shown as mean \pm standard error of the mean. ${ }^{* *}, \mathrm{P}<0.001$.

then added to each well according to the manufacturer's instructions. Absorbance was measured at $490 \mathrm{~nm}$.

\section{Xenotransplantation mice experiments}

BALB/c-nu mice (4-6 weeks old, female) were purchased from Charles River Laboratories (Beijing, China), and tumor cells $\left(1 \times 10^{6}\right)$ were subcutaneously injected into the dorsal or ventral flank. The mice were observed every three days. Two weeks later the mice were sacrificed and the tumor were dissected. All animal research was performed in accordance with the detailed rules approved by the Animal Care and Use Ethnic Committee, and all efforts were made to minimize animal suffering.

\section{Statistical analysis}

Results are shown as mean \pm standard error of the mean. Statistical analysis among different groups was assessed by student's $t$-test. $\mathrm{P}<0.05$ was defined as statistically significant.

\section{Results}

\section{CD276 is a potential cervical CSC marker}

In this study, the HeLa cell line was used to represented cervical carcinoma cell line. To generate the sphereforming cells, HeLa cells were plated in stem cell medium in 6-well plates with density adjusted to 10,000 cells/well. A typical sphere-forming cell was generated under this condition (Figure 1A). After harvesting the sphere-forming cells and control HeLa cells, RT-qPCR were performed to determinate the expression of CD276 and stem cell biomarker OCT4 and SOX2 (Figure 1B). The results shown that the expression of both OCT4 and SOX2 in sphereforming cells was 3 times more than control cells, which indicated the activity of sphere formed cell resembled stem cells. Noticeably, CD276 is considerably higher expressed in sphere-forming cells than control cells, which suggested that CD276 might act as a potential stem cell marker in HeLa cells.

\section{CD276 promotes the self-renewal process of the HeLa cells}

Sphere-forming possess is the milestone of self-renewal process in cancer cells (23). To evaluate whether the expression of CD276 affects the sphere forming possess of HeLa cells, we regulated CD276 expression via two independent but opposite approaches, siRNA and extraneously transforming CD276-containing plasmid, and expression of CD276 and sphere-forming cells have been quantified. The RT-qPCR results (Figure 2) demonstrated that the both siRNA and CD276 vector could successfully regulate CD276 expression (Figure $2 A, C$ ). While the CD276 expression was downregulated, the number of cells that formed sphere significantly decreased (Figure $2 B$ ). On the contrary, overexpression of CD276 led to a significant increase in the abundance of formed spheres (Figure 2D). These results indicated the important role of CD276 in 
A

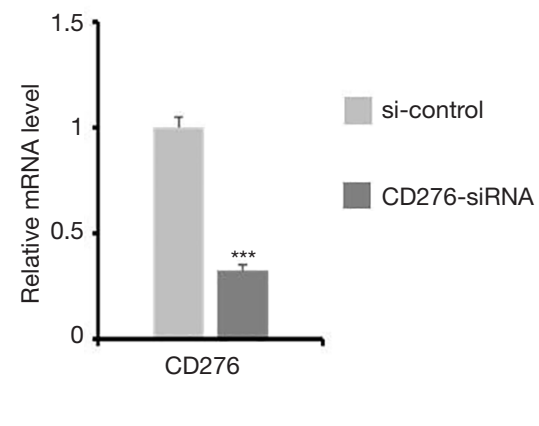

C

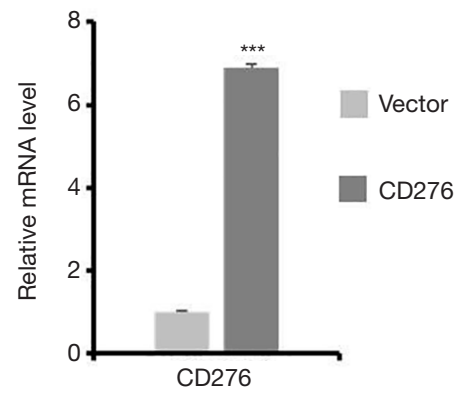

B

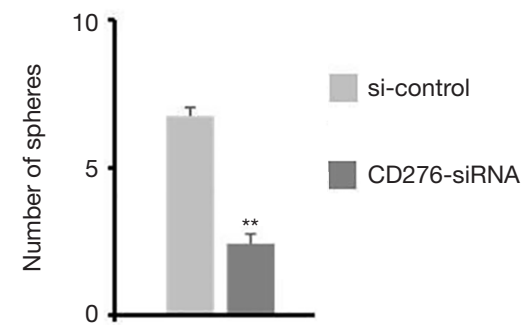

D

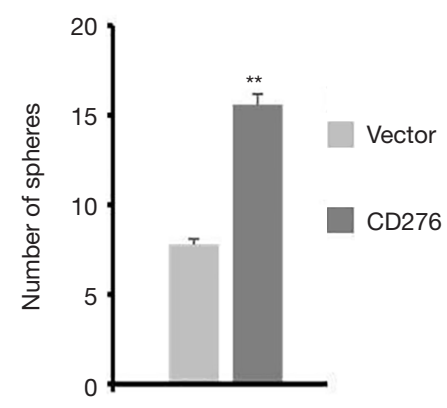

Figure 2 CD276 plays an important role in self-renewal process of the tumor cells. (A) siRNA downregulates expression of CD276 in Hela cells; (B) the number of sphere-forming cells decreased after CD276 downregulation; (C) overexpression of CD276 in Hela cells; (D) the number of sphere-forming increased after CD276 overexpression. Results are shown as mean \pm standard error of the mean. **, $\mathrm{P}<0.01$; ${ }^{* * *}$, $\mathrm{P}<0.001$.

HeLa cells' renewal.

\section{CD276 serves as an oncogene in HeLa cells}

To further investigate the bioactivity of CD276 in HeLa cells, we performed the colony formation assay and MTT assay after siRNA treatment or plasmid transformation. Knockdown of CD276 in HeLa cells remarkably inhibited the cell colony formation compared with control test (Figure $3 \mathrm{~A}$ ). Plasmid transformation of CD276, reversely, promoted the colony formation of HeLa cells extraordinarily (Figure $3 A$ ). Furthermore, MTT assay also indicated that downregulation of CD276 caused the decrease of cell viability while overexpression enhanced cell viability in 24-72 hours post-treatment (Figure 3B). These data demonstrated that CD276 is an oncogene which increases the metastasis of HeLa cells.

\section{CD276 protects HeLa cells in chemotherapy}

Previous studies concluded that CSCs greatly contributed on chemotherapy resistance in variety of cancers. To explore whether CD276 is involved in chemotherapy resistance of HeLa cells, we treated HeLa cells with cisplatin while increase or decrease expression of CD276 respectively. CD276 siRNA significantly increased cytotoxicity of cisplatin in HeLa cells, while CD276 plasmid transformation decreased its toxicity (Figure $4 A$ ). Meanwhile, MTT assay showed similar results, the expression level of CD276 was positively correlated to the cell viability after cisplatin treatment (Figure $4 B$ ). These findings suggested that CD276 protected HeLa cells in chemotherapy.

\section{Exogenous expression of CD276 increases tumor growth in xenotransplantation mice}

To evaluate the CD276's influence on cervical carcinoma in vivo, we assessed the tumor size in a xenotransplantation mouse model. 6-week BALB/c-nu mice were used to transplant either wildtype or CD276 overexpression HeLa cells were into the dorsal or ventral flank. Significantly, 

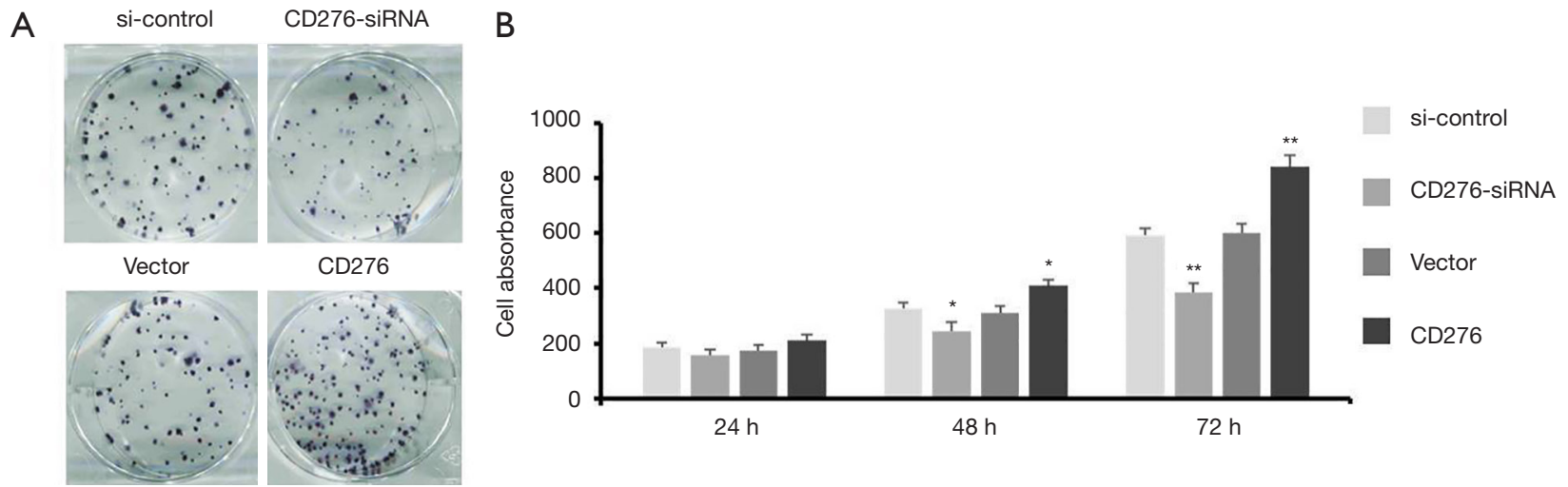

Figure 3 CD276 serves as an oncogene in Hela cells. (A) CD276 affects colony formation in Hela cells; (B) downregulation of CD276 blocks tumor cell proliferation and vice versa. Results are shown as mean \pm standard error of the mean. ${ }^{*}, \mathrm{P}<0.05 ;{ }^{* *}, \mathrm{P}<0.01$.
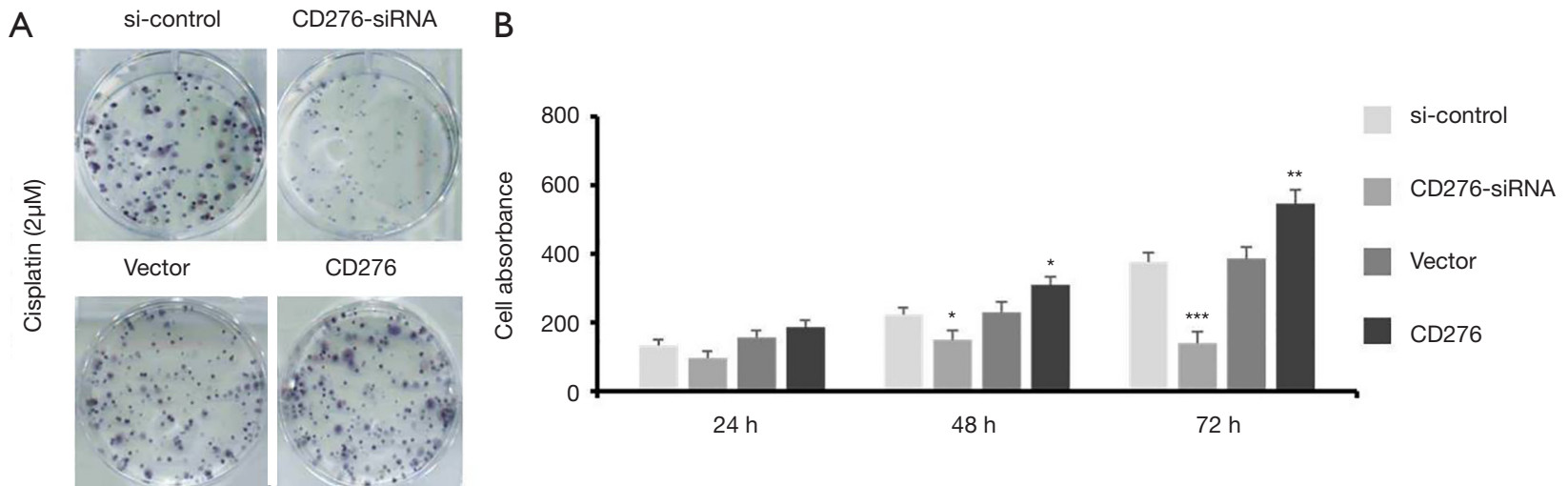

Figure 4 CD276 protects tumor cells against chemotherapy. (A) CD276 promotes colony formation in Hela cells during cisplatin treatment; (B) downregulation of CD276 blocks tumor cells proliferation during cisplatin treatment, and vice versa. Results are shown as mean \pm standard error of the mean. *, $\mathrm{P}<0.05 ;{ }^{* *}, \mathrm{P}<0.01 ; * * *, \mathrm{P}<0.001$.

all the tumors formed in CD276 overexpression group displayed a larger size with heavier weight compared to control group (Figure 5). These results indicated the overexpression of CD276 promoted cervical cancer proliferation and growth in vivo.

\section{Discussion}

In this present study, we demonstrated that CD276 inhibited the proliferation and self-renewal capacity of HeLa sphereforming cells, and also involved in chemotherapy resistance. This evidence suggested that CD276 might be a critical factor in cervical CSCs formation.

Despite the widespread of screening programs, cervical cancer remains the third most common female cancer in developing countries $(1,2)$. Currently, strategies targeting cervical CSCs have been considered as a new therapy target with rising hope.

The abundance of CSCs is highly associated with cancer growth, invasion, and the resistance of conventional cancer therapy such as chemotherapy and radiotherapy. To date, treatment targeting CSCs has been considered as a novel strategy for clinical cancer therapy against cancers including cervical carcinoma. However, the molecular mechanism between CSCs and cervical carcinoma is still awaiting further clarification.

Conventionally, CD276 has been considered as an immune check point molecular (20). Recently, increasing evidence supports that CD276 is an oncogene and directly increases cancer development $(20,24,25)$. Benzon et al. found that the expression level of CD276 is correlated with malignant phenotype of prostate cancer (26). In other 

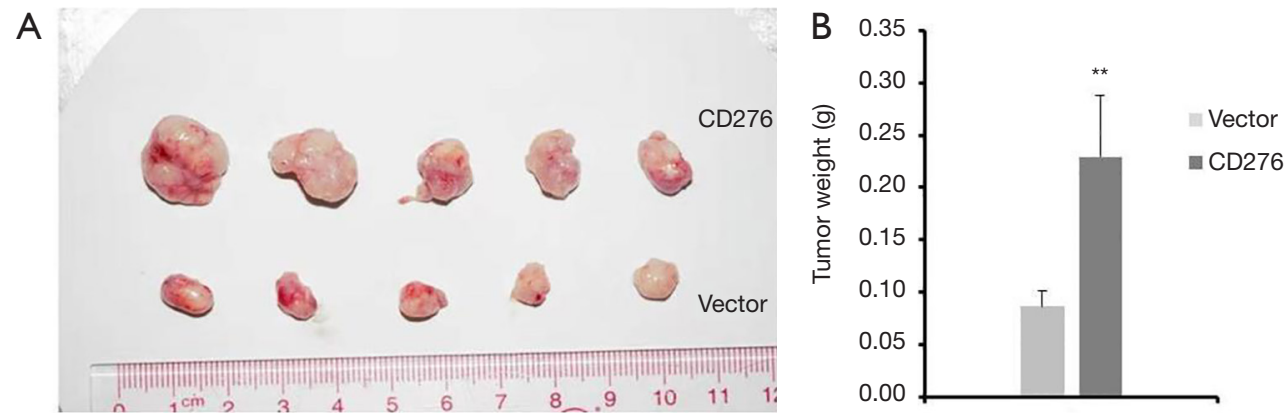

Figure 5 CD276 increases tumor growth in Xenotransplantation mice. Mean $\pm \mathrm{SD}$; ${ }^{* *}, \mathrm{P}<0.01$.

hand, downregulating CD276 expression could significantly suppress the cell proliferation and increase chemotherapy sensitivity in various cancers, such as prostate, breast, gastric, colorectal, melanoma and cervical $(18,20,27)$. However, few researches focus on the correlation between CD276 and CSCs, even though they exhibit similar functions including accelerating cancer invasion and recrudesce, as well as increasing chemotherapy resistance.

The subpopulation of sphere-forming cells performs most stem cells' properties, which is instrumental for stem cell studies. In HeLa cells, the sphere-forming cells express various stem cell markers in an extremely high amount, including OCT4 and SOX2. Thus, in this present study, we firstly proved the increasing expression of CD276 in sphereforming cells of HeLa cell line. To further evaluate the effect of CD276 on cervical carcinoma, we overexpressed CD276 by using pcDNA3.1-CD276, and knockdown CD276 via siRNA. The results indicated that the expression level of CD276 is positively correlated with the proliferation, selfrenewal, and oncogenesis in HeLa cell line.

Previously, several evidences suggested that CD276 also involved in chemotherapy resistance in several cancers. Liu et al. reported CD276 increases paclitaxel sensitivity in breast cancer (28). Zhang et al. reported that inhibition of CD276 reverses oxaliplatin resistance in colorectal cancer (29). To investigate whether CD276 is responsible for the chemotherapy resistance in cervical carcinoma, we performed a cisplatin treatment after regulating CD276 expression level by siRNA or plasmid transformation, respectively. The results suggested that CD276 increase cisplatin resistance in HeLa cell.

\section{Conclusions}

In conclusion, this presented study demonstrated that
CD276 positively regulate the proliferation, self-renewal, and oncogenesis, as well as chemotherapy resistance in HeLa cells. These findings provide a solid evidence for the relationship between CD276 and cervical carcinoma, and also reveal the potential for CD276 as a new therapeutic target.

\section{Acknowledgments}

We thank Liu Yang for her technical assistant during the animal experiment.

Funding: This study was funded by Strategic Priority Research Program of Chinese Academy of Sciences (CAS) (contact grant number: XDA16040602) and National Key R\&D Program of China (contact grant number: 2016YFC1101202).

\section{Footnote}

Reporting Checklist: The authors have completed the ARRIVE reporting checklist. Available at http://dx.doi. org/10.21037/tcr-19-2910

Data Sharing Statement: Available at http://dx.doi. org/10.21037/tcr-19-2910

Conflicts of Interest: All authors have completed the ICMJE uniform disclosure form (available at http://dx.doi. org/10.21037/tcr-19-2910). The authors have no conflicts of interest to declare.

Ethical Statement: The authors are accountable for all aspects of the work in ensuring that questions related to the accuracy or integrity of any part of the work are appropriately investigated and resolved. Experiments 
were performed under a project license [No. 2019(A)027] granted by committee Chinese National Institute for Food and Drug Control, in compliance with Regulations for the Administration of Affairs Concerning Experimental Animals published by the Chinese Government.

Open Access Statement: This is an Open Access article distributed in accordance with the Creative Commons Attribution-NonCommercial-NoDerivs 4.0 International License (CC BY-NC-ND 4.0), which permits the noncommercial replication and distribution of the article with the strict proviso that no changes or edits are made and the original work is properly cited (including links to both the formal publication through the relevant DOI and the license). See: https://creativecommons.org/licenses/by-nc-nd/4.0/.

\section{References}

1. Moshkovich O, Lebrun-Harris L, Makaroff L, et al. Challenges and Opportunities to Improve Cervical Cancer Screening Rates in US Health Centers through PatientCentered Medical Home Transformation. Adv Prev Med 2015;2015:182073.

2. Pimple S, Mishra G, Shastri S. Global strategies for cervical cancer prevention. Curr Opin Obstet Gynecol 2016;28:4-10.

3. Marx J. Cancer research. Mutant stem cells may seed cancer. Science 2003;301:1308-10.

4. Friel AM, Sergent PA, Patnaude C, et al. Functional analyses of the cancer stem cell-like properties of human endometrial tumor initiating cells. Cell Cycle 2008;7:242-9.

5. Batlle E, Clevers H. Cancer stem cells revisited. Nat Med 2017;23:1124-34.

6. Carnero A, Garcia-Mayea Y, Mir C, et al. The cancer stem-cell signaling network and resistance to therapy. Cancer Treat Rev 2016;49:25-36.

7. Wang T, Shigdar S, Gantier MP, et al. Cancer stem cell targeted therapy: progress amid controversies. Oncotarget 2015;6:44191-206.

8. Yao T, Lu R, Zhang Y, et al. Cervical cancer stem cells. Cell Prolif 2015;48:611-25.

9. Tyagi A, Vishnoi K, Mahata S, et al. Cervical Cancer Stem Cells Selectively Overexpress HPV Oncoprotein E6 that Controls Stemness and Self-Renewal through Upregulation of HES1. Clin Cancer Res 2016;22:4170-84.

10. Gu W, Yeo E, McMillan N, et al. Silencing oncogene expression in cervical cancer stem-like cells inhibits their cell growth and self-renewal ability. Cancer Gene Ther
2011;18:897-905.

11. Bigoni-Ordonez GD, Ortiz-Sanchez E, Rosendo-Chalma $\mathrm{P}$, et al. Molecular iodine inhibits the expression of stemness markers on cancer stem-like cells of established cell lines derived from cervical cancer. BMC Cancer 2018;18:928.

12. Chhabra R. Cervical cancer stem cells: opportunities and challenges. J Cancer Res Clin Oncol 2015;141:1889-97.

13. de Campos RP, Schultz IC, de Andrade Mello P, et al. Cervical cancer stem-like cells: systematic review and identification of reference genes for gene expression. Cell Biol Int 2018;42:139-52.

14. Cao HZ, Liu XF, Yang WT, et al. LGR5 promotes cancer stem cell traits and chemoresistance in cervical cancer. Cell Death Dis 2017;8:e3039.

15. Ikeda K, Tate G, Suzuki T, et al. Coordinate expression of cytokeratin 8 and cytokeratin 17 immunohistochemical staining in cervical intraepithelial neoplasia and cervical squamous cell carcinoma: an immunohistochemical analysis and review of the literature. Gynecol Oncol 2008; 108:598-602.

16. Ali N, Allam H, May R, et al. Hepatitis C virus-induced cancer stem cell-like signatures in cell culture and murine tumor xenografts. J Virol 2011;85:12292-303.

17. Wang W, Li Y, Liu N, et al. MiR-23b controls ALDH1A1 expression in cervical cancer stem cells. BMC Cancer 2017;17:292.

18. Castellanos JR, Purvis IJ, Labak CM, et al. B7-H3 role in the immune landscape of cancer. Am J Clin Exp Immunol 2017;6:66-75.

19. Seaman S, Zhu Z, Saha S, et al. Eradication of Tumors through Simultaneous Ablation of CD276/B7-H3Positive Tumor Cells and Tumor Vasculature. Cancer Cell 2017;31:501-15.e8.

20. Dong P, Xiong Y, Yue J, et al. B7H3 As a Promoter of Metastasis and Promising Therapeutic Target. Front Oncol 2018;8:264.

21. Huang C, Zhou L, Chang X, et al. B7-H3, B7-H4, Foxp3 and IL-2 expression in cervical cancer: Associations with patient outcome and clinical significance. Oncol Rep 2016;35:2183-90.

22. Maeda N, Yoshimura K, Yamamoto S, et al. Expression of $\mathrm{B} 7-\mathrm{H} 3$, a potential factor of tumor immune evasion in combination with the number of regulatory $\mathrm{T}$ cells, affects against recurrence-free survival in breast cancer patients. Ann Surg Oncol 2014;21 Suppl 4:S546-54.

23. Cao L, Zhou Y, Zhai B, et al. Sphere-forming cell subpopulations with cancer stem cell properties in human 
hepatoma cell lines. BMC Gastroenterol 2011;11:71.

24. Liu F, Zhang T, Zou S, et al. B7H3 promotes cell migration and invasion through the Jak2/Stat3/MMP9 signaling pathway in colorectal cancer. Mol Med Rep 2015;12:5455-60.

25. Xie C, Liu D, Chen Q, et al. Soluble B7-H3 promotes the invasion and metastasis of pancreatic carcinoma cells through the TLR4/NF-kappaB pathway. Sci Rep 2016;6:27528.

26. Benzon B, Zhao SG, Haffner MC, et al. Correlation of B7-H3 with androgen receptor, immune pathways and

Cite this article as: Shi J, Zhao H, Lian H, Ke L, Zhao L, Wang C, Han Q. CD276 (B7H3) improve cancer stem cells formation in cervical carcinoma cell lines. Transl Cancer Res 2021;10(1):65-72. doi: 10.21037/tcr-19-2910 poor outcome in prostate cancer: an expression-based analysis. Prostate Cancer Prostatic Dis 2017;20:28-35.

27. Flem-Karlsen K, Fodstad O, Tan M, et al. B7-H3 in Cancer - Beyond Immune Regulation. Trends Cancer 2018;4:401-4.

28. Liu H, Tekle C, Chen YW, et al. B7-H3 silencing increases paclitaxel sensitivity by abrogating Jak2/Stat3 phosphorylation. Mol Cancer Ther 2011;10:960-71.

29. Zhang $P$, Chen Z, Ning K, et al. Inhibition of B7-H3 reverses oxaliplatin resistance in human colorectal cancer cells. Biochem Biophys Res Commun 2017;490:1132-8. 